\title{
Políticas públicas de revitalização urbana: uma abordagem no turismo e lazer das cidades de Natal/ $\mathrm{RN}$ e Recife/PE
}

\section{Urban revitalization public policies: an approach in tourism and leisure of the cities of Natal/RN and Recife/PE}

Aylana Laíssa Medeiros Borges - Doutoranda em Turismo, pela Universidade Federal do Rio Grande do Norte (UFRN). Professora do curso de tecnologia em Gestão de Turismo da Universidade Federal do Tocantins (UFT). E-mail: aylanaborges@outlook.com.

Luana Dayse de Oliveira Ferreira - Mestra em Turismo, pela Universidade Federal do Rio Grande do Norte (UFRN). E-mail: luana.ldof2@hotmail.com.

Wilker Ricardo de Mendonça Nóbrega - Doutor em Ciências Socioambientais, pelo Núcleo de Altos Estudos Amazônicos da Universidade Federal do Pará (NAEA/UFPA). Professor do Departamento de Turismo da Universidade Federal do Rio Grande do Norte (UFRN). E-mail: wilkernobrega@yahoo.com.br.

\section{Resumo}

O presente artigo tem como objetivo identificar as políticas públicas de revitalização das cidades de Natal/RN e Recife/PE. Para tanto, utilizaram-se as pesquisas do tipo bibliográfica e documental, além de sites oficiais que auxiliaram para o levantamento dos dados. Como resultados, observou-se uma tentativa de desenvolver e efetivar as políticas de forma intersetorial, a partir do envolvimento de diferentes secretarias ou departamentos do governo; percebeu-se a busca por envolver diferentes atores no processo de elaboração das políticas, em destaque a comunidade local, tanto para fins de elaboração dessas políticas quanto com relação as definições sobre a democratização do uso dos espaços; e notou-se uma resistência por parte do poder privado em investir em políticas destinadas para locais considerados de vulnerabilidade e que concentram moradores de baixa renda. Afirma-se que a relação entre setor público e privado precisa ser melhorada no sentido de convencimento de investimentos desses últimos em áreas que carecem de ser desenvolvidas como forma de contribuição da qualidade de vida da comunidade local e dos potenciais visitantes/turistas.

\section{Palavras-chave}

Políticas Públicas. Revitalização. Turismo. Lazer. Espaços públicos.

\begin{abstract}
This article aims to identify the public policies of revitalization of the cities of Natal/RN and Recife/PE. In to do so, we used bibliographic and documentary surveys, as well as official sites that helped to collect the data. How he behaved as an attempt to develop intersectoral policy policies, how he cared about secretariats or government departments; the aim was to involve different actors in the policy-making process, highlighting the local community, both for the purpose of elaborating these policies and in relation to the definitions on the democratization of the use of spaces; and there was a resistance on the part of the private power to invest in policies aimed at places considered to be vulnerable and that concentrate low-income residents. It was agreed that the relationship between the public and private sectors needs to be improved to convince them to invest in areas that need to be developed as a contribution to the quality of life of the local community and potential visitors/tourists.
\end{abstract}

\section{Keywords}

Public Policy. Revitalization. Tourism. Leisure. Public Space. 


\section{INTRODUÇÃO}

O turismo participa da política pública de gestão urbana de uma cidade em diferentes níveis, por exemplo, como possibilidade de desenvolvimento econômico e social, e a partir do estímulo ao lazer que pode ser consumido pela comunidade local e pelos turistas e visitantes. Mais do que um potencial patrimonial, o turismo possibilita a reflexão de questões simbólicas nos projetos de revitalização de áreas centrais, destacando a interface entre cidade, sociedade e turismo, bem como a valorização do que foi vivenciado em épocas diversas e a necessidade de reformulação considerando o momento atual.

A integração social apresenta-se como o foco dos projetos de revitalização dos espaços, uma vez que se procura oferecer ambientes que possam ser compartilhados e usufruídos por toda sociedade, sem distinção de classe, gênero, cor, idade, condição financeira, entre outros.

O entendimento acerca das características das políticas públicas de revitalização e seus aspectos de desenvolvimento local carecem de atenção e debate, pois são capazes de transformar e dar diferentes sentidos de uso aos espaços já existentes. As cidades vivenciam um rápido e exigente processo de transformação estrutural, especialmente devido à globalização e, muitas vezes, seguindo a padronização hegemônicas no qual é necessário refletir como as comunidades estão sendo consideradas em meio a estas alterações e se os valores históricos e culturais de cada lugar estão sendo de fato apreciados em tais políticas.

Com base nesse cenário, analisar as políticas neoliberais que estão influenciando, ou podem vir a influenciar a revitalização de áreas urbanas, compõe o tema central deste estudo. Nesta perspectiva, delimitou-se para esta pesquisa as cidades de Natal/RN e de Recife/PE, por possuírem uma localização geográfica próxima, mas principalmente por disporem de atrativos turísticos semelhantes, além de terem elementos de valor histórico e cultural singulares que merecem ser valorizados pelas políticas elaboradas e propostas, uma vez que são meios motivadores de deslocamentos para a prática do turismo e/ou lazer.

Quanto aos aspectos metodológicos, este estudo se caracteriza como uma pesquisa qualitativa, baseada na análise de documentos que abrangem o estudo dos casos de Natal/RN e Recife/PE. Acredita-se que uma investigação sobre as políticas públicas locais, em especial, de revitalização, pode trazer ponderações sobre sua efetividade, além de identificar documentos que necessitam ser revistos e alterados, ou que precisam ser melhor planejados, pensando em atingir os objetivos de maneira mais eficaz. 
Este artigo traz o resultado de uma investigação cujo objetivo central foi analisar as políticas públicas de revitalização das áreas urbanas com apelo turístico e de lazer das cidades de Natal/RN e Recife/PE. Para tanto, delimitouse como objetivos intermediários: identificar as políticas públicas de revitalização das áreas urbanas turísticas e de lazer dos municípios de Natal e Recife; verificar quais os atores envolvidos no processo de elaboração das políticas públicas de revitalização existentes nos municípios; e, por fim, delinear os aspectos relacionais entre as políticas públicas de revitalização existentes nas referidas localidades.

É importante esclarecer que parte deste estudo foi apresentado no I Colóquio Nacional sobre Cidades Litorâneas e Turismo (CILITUR) realizado em Recife/PE. Assim sendo, a essência do trabalho é a mesma, porém realizou-se uma melhoria na estruturação dos aspectos teóricos que oferecem suporte as discussões e ampliou-se os resultados encontrados a partir das investigações realizadas.

Dessa maneira, apresentar-se-á, em sequência, uma visão geral dos conteúdos teóricos que embasam este estudo, tratando primeiramente dos aspectos conceituais das políticas públicas de revitalização urbana, turismo e lazer e, depois, das possibilidades de desenvolvimento do turismo e do lazer em áreas urbanas revitalizadas. Dando seguimento, apresenta-se a metodologia da pesquisa, a análise e discussão dos resultados, as considerações finais e as referências utilizadas para este trabalho.

\section{ASPECTOS CONCEITUAIS SOBRE POLÍTICAS PÚBLICAS DE REVITALIZAÇÃO URBANA, TURISMO E LAZER}

O debate dos aspectos conceituais sobre políticas públicas tem um papel relevante para a sociedade diante dos diversos e heterogêneos problemas e desafios para o bem da coletividade. Quanto a esta questão, Souza (2002) entende que não existe uma única, nem melhor definição sobre o que seja política pública.

De acordo com Nóbrega (2006), a conceituação de política pública é complexa e está relacionada a várias questões da sociedade, ou seja, na economia social, segurança ambiental, entre outras, na intervenção do Estado em meio a sociedade, por meio de estratégias de planejamento. Já para Silva (2011) a temática deve ser compreendida como sendo a própria corporificação do Estado por meio de ações, direcionamentos, atuações, projetos que possuam como intenção maior suprir as necessidades humanas. Diante disso, compactuando com a mesma ideia, Bahia e Figueiredo (2013) esclarecem a política pública como um campo do conhecimento que procura orientar o governo para realização de 
ações, destacando a necessidade de analisá-las, para propor mudanças coerentes em meio ao andamento de determinada ação.

Sendo assim, as definições de políticas públicas assumem uma visão holística do tema, uma perspectiva que o todo é mais importante do que a soma das partes, em que indivíduos, instituições, interações, ideologias e interesses contam, mesmo que exista certa diferença sobre a relevância desses fatores (SOUZA, 2002).

Entretanto, nota-se que as políticas públicas estão relacionadas às demandas da sociedade, envolvendo, nesse caso, poder e interesses dos diferentes atores da esfera política que necessitam organizar os processos deliberativos por meio de prioridades para bem-estar social, e direcioná-las a partir de avaliações constantes a fim de verificar sua efetividade. Lowi (1964 apud Secchi, 2014) determinou quatro tipos que auxiliam para o processo analítico das políticas públicas, uma vez que as tipologias de políticas são formas de classificar os conteúdos, os atores, os estilos, as instituições, dentro de um processo de política pública, sendo essas: política regulatória, distributiva, redistributiva e constitutiva.

Diante disso, após a compreensão conceitual sobre a temática e as suas tipologias, cabe uma reflexão sobre como essas políticas públicas se enquadram e interferem no processo de ordenamento urbano, e como a revitalização desses espaços influência na formação da sociedade.

Partindo da compreensão que o sistema político orienta para uma perspectiva de metas e objetivos a serem alcançados em diversos âmbitos, seja social, econômico, cultural, e ambiental, tem-se que a implementação de meios visando atingir objetivos nacionais é o que caracteriza o referido sistema com base em áreas como a saúde, educação, justiça, dentre outros, o lazer (PRONOVOST, 2011).

Em se tratando do lazer, é pertinente esclarecer que as mudanças no âmbito trabalhista, especialmente no que se refere ao surgimento do tempo livre e à utilização desse tempo para atividades de descanso, saúde, fuga da rotina diária e/ou divertimento, converge para uma ênfase na necessidade do lazer para as sociedades modernas, como item importante para dinâmica da vida cotidiana (BAHIA; FIGUEIREDO, 2013).

Contudo, de acordo com os autores, as políticas públicas destinadas para garantia do acesso ao lazer não se encontram necessariamente relacionadas ao planejamento e desenvolvimento do conceito de lazer, podendo ser encontradas nas políticas de democratização da cultura, nas políticas de esporte e lazer, nas políticas de saúde, e, até mesmo, nas políticas de criação e manutenção de espaços públicos. Além disso, Amaral (2018) explica que discutir sobre política pública de lazer está diretamente relacionado a ordenamento urbano, planos diretores e ações decorrentes destes em prol da garantia dos direitos sociais, em especial, do lazer. 
Entende-se que as práticas do lazer acabam sendo desenvolvidas de forma intersetorial, isto é, compondo o quadro de atividades de outros órgãos do governo, e sendo realizadas por diferentes secretarias ou departamentos que constituem uma administração pública.

Conforme Pronovost (2011), há algumas décadas as cidades foram favorecidas com serviços públicos de lazer, isto é, equipamentos foram construídos, fixados ou transformados, tendo sido destinados significativos esforços financeiros. O autor ainda acrescenta que quanto ao próprio lazer, os serviços públicos locais encontram-se em processo de mudança.

A sociedade, desde o final do século XIX, vem passando por mudanças sociais, econômicas e políticas de caráter estrutural, o que resulta em modificações na dinâmica do mercado e, também, na vida das pessoas (LOUREIRO; SOUZA, 2006).

Para Castro e Figueiredo (2013), uma das razões para tais mudanças, considerando os processos de modificação, adaptações estruturais e de funcionalidades, seria em virtude do turismo e, portanto, a percepção de como essa atividade econômica pode influenciar nos debates acerca dos usos dos espaços públicos. Destaca-se que uma crescente preocupação de algumas cidades com seu patrimônio cultural e arquitetônico, no final do século XX, colaborou para a elaboração e execução de planos de revitalização, especialmente de centros históricos (SANTOS; CASTROGIOVANNI, 2010).

O termo revitalização tem sido utilizado como sinônimo de intervenção urbana, sendo considerado abrangente, no qual, é visto como "um conjunto de ações, a fim de permitir a um determinado espaço nova eficiência, novo sentido em seu uso, visando uma melhoria do espaço e do seu entorno" (BEZERRA; CHAVES, 2014, p. 1).

Conforme os autores, diversas intervenções têm acontecido nas áreas centrais das cidades, em centros históricos, áreas de periferia, de preservação, espaços sem uso ou degradados, e lugares de usos comuns à população rica e pobre com o intuito de melhoria estética ou a procura de renovação urbana, baseadas em projetos urbanos que objetivam a requalificação urbana. Dessa maneira, a revitalização urbana vem ganhando força e destaque para a compreensão da dinâmica urbana contemporânea, uma vez que se tem a preocupação de assimilar junto a este processo todo o valor histórico, cultural, e social do lugar.

Em consonância, Nóbrega (2013, p. 92) elucida que "a atividade turística vem ocupando um papel de destaque na economia de várias nações nos diferentes continentes em todo planeta". O autor ainda explica que o poder público vem buscando planejar e gerenciar o setor com o intuito de desenvolver as regiões, considerando as particularidades existentes, e com fins de proporcionar melhorias 
na qualidade de vida de residentes e visitantes, destacando ainda que, em virtude das influências sofridas, a organização urbana vem ganhando diferentes adaptações com relação à dimensão estética e de infraestrutura no planejamento.

Para Leite (2004), as intervenções urbanas que vinham se proliferando nas cidades, nas últimas décadas, correspondiam a políticas de revitalização que tinham como efeito mais perceptível a modificação da paisagem urbana em áreas de entretenimento urbano e de consumo cultural, mas que não demonstravam ser suficientes para compreensão do processo de revalorização de áreas centrais e do patrimônio histórico como espaços turísticos.

Baseadas na recuperação seletiva de elementos do passado, de acordo com a conveniência do presente, por meio do patrimônio edificado e do resgate de manifestações culturais, a gentrificação e a segregação social do espaço são apontadas por Harvey (2005) como uma consequência de projetos urbanos pósmodernos voltados para uma excessiva orientação de mercado, conduzidos pelo valor econômico e pelo poder político diferenciado de segmentos sociais específicos.

Com isso, percebe-se que o mercado contemporâneo baseado em aspectos da globalização, ou ainda de aparências padronizadas, passou a requerer esforços no sentido de transformações locais para despertar determinados interesses, em especial em âmbito econômico, de modo a deter investimentos do setor público e privado. E o turismo passou a ser visto como oportunidade de desenvolvimento nesse mercado, a partir de elementos locais organizados, porém devendo ser apresentados sob uma lógica de estratégias diversas com o intuito de despertar uma curiosidade e/ou motivação para o deslocamento e a consequente visitação de um destino.

\section{POSSIBILIDADES DE DESENVOLVIMENTO DO TURISMO E LAZER EM ÁREAS URBANAS REVITALIZADAS}

As mudanças ocorridas da estrutura social industrial para a pós-industrial moderna, sobre as questões relacionadas ao trabalho e ao tempo livre, começaram a emergir no contexto social. Assim, os valores sociais básicos passaram a se mover do mundo do trabalho para buscar refúgio no campo do ócio, enquanto os avanços tecnológicos auxiliaram para o desenvolvimento do turismo (MACCANNEL, 2003).

Dessa forma, o turismo e o lazer são fenômenos que concretizam uma nova necessidade criada pelo homem pós-moderno e propõem uma nova dinâmica para as cidades. De acordo com Dumazedier (1994, p. 38), “o turismo é um fenômeno histórico sem precedentes, na sua extensão e no seu sentido, é uma 
das invenções mais espetaculares do lazer da sociedade moderna". Figueiredo (2009) também identifica o turismo como a forma de viagem exclusiva, advindo da modernidade e sendo um pilar da pós-modernidade.

Marcellino (2008) e Silva (2004) acreditam na importância do entendimento do lazer na sociedade, conceituando-o como sendo uma cultura vivenciada (praticada, fruída ou conhecida) no tempo disponível das obrigações profissionais, escolares, familiares e sociais, que possibilitam, dentre tantas alternativas diferentes, a realização de atividades físicas, manuais, sociais, intelectuais e artísticas. Destaca-se, ainda, que o lazer, na visão dos autores, está diretamente ligado a elementos como tempo e atitude, já que o lazer consiste em ações desenvolvidas no tempo livre, diferentemente do puro ócio que se trata de um estado de contemplação, sem a necessidade da execução de ações. Entende-se que o aspecto cultural mencionado não minimiza apenas os conteúdos artísticos, mas sim, aborda diversos conteúdos culturais.

Além disso, outro aspecto relevante refere-se ao lazer e turismo como direito garantido na sociedade, estando registrado na Constituição da República Federativa do Brasil, na qual é caracterizado como uma atividade democratizada (BRASIL, 1988). Conforme Marcellino (2008, p. 15) "para a efetivação das características do lazer, é necessário, antes de tudo, que ao tempo disponível corresponda um espaço disponível", podendo ser equipamentos públicos e privados, específicos ou não específicos do lazer ${ }^{1}$.

Tendo em vista que a prática do lazer necessita de tempo livre e espaço disponível, levando em consideração a relação existente entre lazer na sociedade moderna e urbanização, pode-se verificar alguns descompassos que foram derivados do crescimento das cidades, e causados pela aceleração imediata do processo de modernização.

Com relação a espaços disponíveis, Castro e Figueiredo (2013) colocam que além das áreas de lazer e circulação tradicionais existentes (praças, jardins, parques, logradouros, lagos, por exemplo), outros espaços são criados configurando equipamentos urbanos públicos ou semipúblicos (roteiros são criados, praças são construídas, locais para comprar são estabelecidos, para "conhecer" a cultura local, e para saborear itens gastronômicos do lugar).

Vale salientar que, para Marcellino (2008), a preocupação com os efeitos nocivos a estrutura social das cidades, causados pelo processo de urbanização, é um fato, e que as ações predatórias, ocasionadas pelos interesses imediatistas,

Equipamentos não específicos - entende-se que não foram criados para a prática das atividades de lazer, mas que depois tiveram sua destinação específica alterada. Equipamentos específicos são construídos com a finalidade da prática do lazer. 
provocam problemas sérios que afetam a qualidade de vida e o lazer das populações, contribuindo para a violência e a falta de segurança.

O modo de produção dominante na sociedade ocidental é o sistema capitalista, que é baseado na busca de lucro e rentabilidade (VASCONCELOS, 2005, p. 49). Todo esse processo acaba deixando de lado a observância de espaços fragilizados, em uma perspectiva de saneamento básico, desenvolvimento econômico, qualidade mínima em termos de saúde, de lugares que estão e permanecem sem investimentos e propostas de avanços das condições de lazer, para focar em espaços potencialmente favoráveis.

Dessa maneira, Silva (2004, p. 4) esclarece que "a violência acontece muito mais nos bairros onde não existem alternativas de lazer, e que se intensifica nos finais de semana", período em que, normalmente, o homem está em seu momento de descanso em relação ao trabalho.

Percebe-se, pois, a relevância do incentivo ao lazer, e a pertinência da formulação e manutenção das políticas públicas existentes, uma vez que, por meio de programas e projetos será possível a concretização de ações. Esclarecendo que o turismo considera todas as inter-relações acontecidas em um destino, desde a "interação entre fixos (território, paisagem etc.) e fluxos (capital, pessoas, padrões e valores culturais) que influenciam as diferentes esferas da organização socioespacial" (VASCONCELOS, 2005, p. 49).

Moragas e Moragas (2007) compreendem que as políticas públicas de lazer possuem um sentido maior como a melhoria da qualidade de vida da população, pressupõem ainda que é possível uma adoção de uma visão humanística do urbano, em que a cidade é vista como um "habitat", onde o homem vive e aspira seu lazer. Nesta lógica, faz-se importante a ordenação e ocupação do território, assim como a localização de forma estratégica dos equipamentos de lazer para que sirvam de estímulo para utilização pela população, e a preservação do patrimônio ambiental urbano.

Conforme Silva (2004, p. 10), "os espaços de lazer significam vida na cidade, notadamente na periferia, para aqueles que sobrevivem precariamente", mas se observa que esses espaços, são também manipulados pelo poder público.

Entende-se que o lazer, com suas particularidades, contribui de forma prazerosa no processo de valorização e preservação do patrimônio, além de cumprir um relevante papel na revitalização dos espaços e equipamentos, tornando fundamental a consideração dos patrimônios artísticos, arquitetônicos e urbanísticos, visto que faz parte da memória das cidades e é capaz de enobrecer a paisagem urbana, enaltecer a cultura e pertença ao lugar. "Os espaços urbanos para além das formas urbanas e originárias de estratégias econômicas e políticas”, é também uma conquista do lazer (SILVA, 2004, p. 5). 
Neste contexto, Moragas e Moragas (2007) retratam o lazer como algo que é inerente ao homem, e revela que a estrutura da cidade deveria proporcionar uma humanização, que lhe foi tirada por causa do desenvolvimento acelerado provocado pela industrialização. Atrelado a este fato, o processo tecnológico em escala global acaba por redefinir o formato das diversas relações (familiares, amizade, trabalho, lazer) existentes na sociedade, surgindo, muitas vezes, um sistema bem articulado, porém excludente que implica mais uma vez na elaboração e execução de ações que estimulem uma realidade menos virtual e mais humanizada. (SILVA, 2004; VASCONCELOS, 2005)

Para Marcellino (2008, p. 20), “o patrimônio ambiental urbano, desde que preservado e revitalizado, pode e deve se constituir em novos equipamentos específicos de lazer". E a utilização desses patrimônios revitalizados, conforme o autor, auxilia de maneira significativa para proporcionar uma vivência mais rica do ambiente urbano, descaracterizando a monotonia dos conjuntos de comunidades, e estabelecendo pontos de referência e vínculos efetivos.

Além disso, "antigos espaços degradados das cidades estão sendo revitalizados e revividos como local de lazer" (SILVA, 2004, p. 5). Nesse sentindo, vê-se a possibilidade de promover a preservação da identidade local, ao passo que se mantém ou, até mesmo, aumenta-se o potencial turístico das cidades.

Barretto (2013) explica que os espaços revitalizados têm levado a uma associação com o turismo, pois na medida em que acontecem as mudanças do processo de revitalização, ocorrem transformações em lugares de lazer urbano e, possivelmente, em atrativos turísticos.

Diante disso, as experiências de revitalização urbana em espaço de potencial turístico promovem a valorização paisagística, fomentando, assim, o desenvolvimento local e tornando o ambiente mais competitivo. O elemento integrador deve existir, ou seja, a busca de espaços públicos que tanto os residentes quanto turistas sintam-se à vontade para praticar as variadas formas de lazer. Além disso, destaca-se que o papel da população nesse processo de revitalização está diretamente relacionado ao bom desempenho da elaboração da política pública que deve objetivar a concretização de um projeto de revitalizar o espaço sem descaracterizar os aspectos culturais e identidade local.

\section{METODOLOGIA}

Como fonte de embasamento teórico, a investigação bibliográfica desenvolvida neste artigo analisou referências relacionadas às seguintes temáticas: políticas públicas, planejamento e desenvolvimento local, e revitalização de áreas urbanas, especialmente no que tange à utilização destes espaços para o turismo e o lazer. 
A fim de analisar as políticas públicas de revitalização das áreas urbanas de turismo e lazer das cidades de Natal e Recife, foram levantados por meio de pesquisa documental (GODOY, 1995) os dados registrados e disponibilizados pelas prefeituras municipais das referidas cidades. Tratou-se da análise de informações das secretarias municiais de meio ambiente e urbanismo, comunicação social, turismo e serviços urbanos; dos conselhos municipais de turismo; além das secretarias estaduais de infraestrutura e do governo federal, sob a coordenação do Ministério do Planejamento.

Os dados coletados foram analisados qualitativamente (RICHARDSON, 1999) e apresentaram os programas, os projetos e as ações elaborados pelo poder público visando a utilização de áreas urbanas para o turismo e o lazer. Desta forma, tornou-se possível identificar as políticas públicas de revitalização das áreas urbanas turísticas e de lazer dos municípios de Natal e Recife; e verificar quais os atores envolvidos no processo de elaboração das políticas públicas de revitalização existentes nestes municípios.

Diante da composição deste cenário, utilizou-se a análise de conteúdo (FLICK, 2009) como instrumento para o delineamento dos aspectos relacionados entre as políticas públicas de revitalização existentes em Natal e Recife, cidades que compõem o estudo de caso (GODOY, 1995) do presente artigo.

Considerando os objetivos citados e com o intuito de melhor apresentar os resultados da pesquisa, foram construídos dois momentos de análise, primeiramente a identificação das políticas públicas de revitalização das áreas urbanas de Natal e Recife e apresentação dos atores envolvidos na elaboração e/ ou implementação das políticas públicas existentes; e, em seguida, a apresentação dos aspectos relacionais das políticas apresentadas.

\section{ANÁLISE E DISCUSSÃO DOS RESULTADOS: POLÍTICAS PÚBLICAS DE REVITALIZAÇÃO E ATORES ENVOLVIDOS NA ELABORAÇÃO E IMPLEMENTAÇÃO DAS POLÍTICAS EM NATAL E RECIFE}

Antes de adentrar nas políticas públicas de revitalização das cidades de Natal e Recife, vê-se como pertinente levantar alguns aspectos característicos locais a fim de apresentar um pouco das configurações urbanas dos referidos destinos.

A cidade de Natal, capital do Rio Grande do Norte, foi fundada em 1599, às margens do rio Potengi, possui área de $167,401 \mathrm{~km}^{2}$, com população estimada no ano de 2019 de 884. 122 habitantes (IBGE, 2019). O litoral potiguar possui uma extensão aproximada de $410 \mathrm{~km}^{22}$.

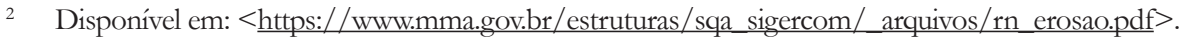


A urbanização da cidade teve início no século XX com o governo de Pedro Velho (1892-1896), que visualizou no bairro de Petrópolis e Tirol características de uma cidade nova, pronta para ser edificada e planejada. Por meio do Plano Polidrelli idealizou-se um bairro novo para o município, somando-se aos existentes Cidade Alta e Ribeira, o qual ficou conhecido como Cidade Nova.

A partir desse plano houve mudanças físicas na cidade, afetando a distribuição geográfica das camadas sociais, pois na área denominada de Cidade Nova surgiu a elite natalense, enquanto, nas margens do oceano atlântico se montava um conjunto de favelas (TAQUARY; FAGUNDES, 2010).

Nos dias atuais a gestão do município de Natal é regida sob Plano Diretor instituído pela Lei Complementar n⿳⺈ 082, de 21 de junho de 2007, sendo um instrumento básico da política de desenvolvimento urbano, com objetivo explícito no Art. $2^{\circ}$ de garantir pleno desenvolvimento das funções sociais, e ambientais da cidade e da propriedade, garantindo um uso socialmente justo e ecologicamente equilibrado do seu território, de forma a assegurar a todos os seus habitantes, condições de qualidade de vida, bem-estar e segurança. Assim, definem-se as regras de uso e ocupação do solo, contemplando aspectos como serviço de saúde, habitação, meio ambiente e limpeza urbana (BRASIL, 2007).

Verifica-se que o Plano Diretor da Cidade do Natal, Lei complementar $\mathrm{n}^{\circ}$ 082, de 21 de junho de 2007, art. 3으, assegura-se a preocupação com a preservação, a proteção e a recuperação do meio ambiente e da paisagem urbana, com o intuito de garantir a manutenção equilibrada dos recursos naturais, além da qualidade de vida para os habitantes, incentivo à atividade econômica, bem como a proteção ao patrimônio histórico e cultural da cidade.

As políticas públicas de revitalização urbana propostas para serem realizadas na cidade de Natal serão apresentadas a seguir e, na sequência, dados sobre Recife foram elencados juntamente com as políticas existentes. Nos Quadros 1 e 2, encontrar-se-ão informações acerca: da secretaria na qual a política foi proposta; dos planos, programas e/ou projetos elaborados; o objetivo de tais documentos; as ações pretendidas e a situação destas propostas.

No Quadro 1, visualiza-se um resumido panorama das políticas de Natal cujo objetivo comum, a ser destacado, é investir na melhoria e gestão dos espaços urbanos. Foi necessária a escolha de apenas algumas das propostas listadas para levantar informações relevantes, considerando o breve espaço de tempo para o desenvolvimento da pesquisa. 
Quadro 1 - Políticas públicas de revitalização urbana de Natal/RN

\begin{tabular}{|c|c|c|c|}
\hline $\begin{array}{l}\text { Secretaria/ } \\
\text { órgão }\end{array}$ & $\begin{array}{l}\text { Plano } \\
\text { Programa } \\
\text { Projeto }\end{array}$ & Objetivo & Ação/situação \\
\hline \multirow{2}{*}{ 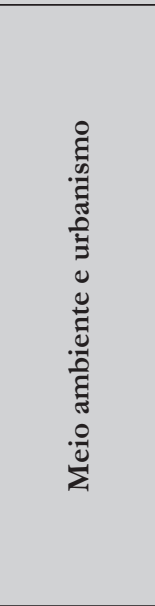 } & $\begin{array}{l}\text { Plano de } \\
\text { ordenamento, } \\
\text { gestão e fiscalização } \\
\text { integrada de Orla de } \\
\text { Ponta Negra/RN } \\
\text { (Proposta 1) }\end{array}$ & $\begin{array}{l}\text { Melhorar a qualidade } \\
\text { ambiental, paisagística e as } \\
\text { condições de uso da praia; } \\
\text { ampliar a atratividade turística; } \\
\text { sanar pendências judiciais. }\end{array}$ & $\begin{array}{l}\text { A orla foi dividida em } 10 \\
\text { trechos; Estabelecimentos } \\
\text { de normas gerais relativas a } \\
\text { localização, funcionamento } \\
\text { aplicadas as atividades } \\
\text { desenvolvidas no espaço } \\
\text { público. } \\
\text { Projeto em andamento. }\end{array}$ \\
\hline & $\begin{array}{l}\text { "Nossa Cidade Mais } \\
\text { Limpa" } \\
\text { (Proposta 1.1) }\end{array}$ & $\begin{array}{l}\text { Limpar os monumentos } \\
\text { públicos, retirar as publicidades } \\
\text { ilegais, devolvendo o aspecto } \\
\text { original ao empreendimento. }\end{array}$ & $\begin{array}{l}\text { O Complexo Viário do } 4^{\circ} \\
\text { Centenário, na zona Sul } \\
\text { de Natal; O Viaduto de } \\
\text { Igapó e o viaduto da Praia } \\
\text { do Forte passaram pelo } \\
\text { trabalho de revitalização, } \\
\text { Ponte Newton Navarro e o } \\
\text { Viaduto da Urbana. } \\
\text { Projeto em andamento. }\end{array}$ \\
\hline \multirow{3}{*}{ 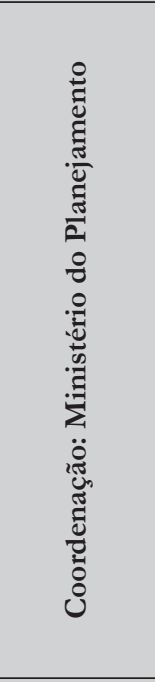 } & $\begin{array}{l}\text { Programa de } \\
\text { Aceleração do } \\
\text { Crescimento/PAC } \\
\text { (Proposta 2) }\end{array}$ & $\begin{array}{l}\text { Ampliar estratégias de } \\
\text { desenvolvimento } \\
\text { posicionar o para } \\
\text { cultural como eixo indutor e } \\
\text { estruturante. }\end{array}$ & $\begin{array}{l}\text { Intervenção em espaços } \\
\text { públicos: } \\
\text { reabilitar e restaurar, } \\
\text { praças; edifícios de us alificar } \\
\text { público; restaurações de } \\
\text { prédios históricos. } \\
\text { Projeto em andamento. }\end{array}$ \\
\hline & $\begin{array}{l}\text { Recuperação dos } \\
\text { banheiros públicos } \\
\text { da Orla de Ponta } \\
\text { Negra } \\
\text { (Proposta 3) }\end{array}$ & $\begin{array}{l}\text { Reparação de danos causados } \\
\text { pela depredação desses } \\
\text { equipamentos públicos. }\end{array}$ & 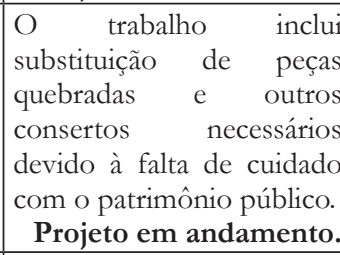 \\
\hline & $\begin{array}{l}\text { Reurbanização } \\
\text { da praça Djalma } \\
\text { Maranhão - Av. do } \\
\text { Contorno } \\
\text { (Proposta 4) } \\
\end{array}$ & $\begin{array}{l}\text { Tornar a área de abrangência } \\
\text { da praça um ponto de atração } \\
\text { turística da cidade }\end{array}$ & $\begin{array}{l}\text { Reformar a praça existente. } \\
\text { Projeto em andamento. }\end{array}$ \\
\hline 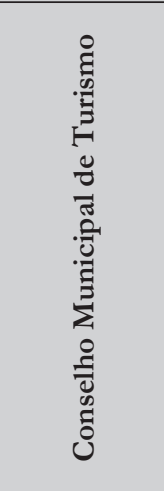 & $\begin{array}{l}\text { Plano de Gestão } \\
\text { Municipal de } \\
\text { Turismo }\end{array}$ & $\begin{array}{l}\text { Propor ações para fortalecer } \\
\text { a área turística de Natal } \\
\text { como importante indutor } \\
\text { de inclusão social, de modo } \\
\text { a elevar a qualidade dos } \\
\text { produtos turísticos, promover } \\
\text { a sua competitividade nos } \\
\text { mercados regional, nacional } \\
\text { e internacional e a geração } \\
\text { de trabalho e renda; além da } \\
\text { requalificação, ampliação e } \\
\text { diversificação da oferta, e o } \\
\text { aumento do gasto turístico e da } \\
\text { receita do município de Natal. }\end{array}$ & $\begin{array}{l}\text { Elaborar planos: plano } \\
\text { de marketing; plano } \\
\text { de fortalecimento } \\
\text { institucional e plano de } \\
\text { desenvolvimento } \\
\text { turismo. }\end{array}$ \\
\hline
\end{tabular}




\begin{tabular}{|c|c|c|c|}
\hline 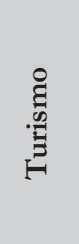 & $\begin{array}{l}\text { "Roteiro Natal } \\
\text { Sagrado e Histórico" }\end{array}$ & $\begin{array}{l}\text { O turismo religioso é um viés } \\
\text { que se descortina tanto para } \\
\text { o natalense, que vai valorizar } \\
\text { mais os templos católicos da } \\
\text { cidade, como para os turistas } \\
\text { que visitam a capital. }\end{array}$ & $\begin{array}{l}\text { O roteiro engloba o Centro } \\
\text { de Natal, passando por } \\
\text { igrejas, memoriais, espaços } \\
\text { de cultura e arte, dentre } \\
\text { outras áreas que retratam } \\
\text { o patrimônio histórico- } \\
\text { cultural da cidade. }\end{array}$ \\
\hline 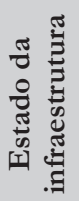 & $\begin{array}{l}\text { Projeto de } \\
\text { reestruturação da } \\
\text { Avenida Engenheiro } \\
\text { Roberto Freire }\end{array}$ & $\begin{array}{l}\text { Reestruturados quatro } \\
\text { quilômetros, entre a BR-304 e } \\
\text { a Rota do Sol (RN-063). }\end{array}$ & Projeto em andamento. \\
\hline
\end{tabular}

Fonte: Dados da pesquisa (2017)

A proposta 1 - Plano de Ordenamento, Gestão e Fiscalização Integrada de Orla de Ponta Negra/RN é instituída pela Secretaria de Meio Ambiente e Urbanismo (SEMURB), intenciona realizar uma reordenação do espaço da orla de Ponta Negra, principal praia urbana e turística de Natal, com base em estudos de capacidade, propondo ações para impedir a prática de atividades potencialmente poluidoras e a utilização indevida do espaço público comum, assim melhorando a qualidade ambiental e paisagística e as condições do uso de Ponta Negra/RN (NATAL, 2017). No plano, a ação será coordenada pela SEMURB e integrada pelas secretarias de Serviços Urbanos e de Saúde (SMS) com a Vigilância Sanitária, de Mobilidade (STTU) e de Defesa Social (SEMDES) com a Guarda Municipal, além de contar com apoio das secretarias de Assistência Social (SEMTAS), Turismo (SETUR), Cultura (SECULT), Serviços Urbanos (SENSUR), e Procon Municipal e da Secretaria de Obras e Infraestrutura (SEMOV) (SEMURB, 2017).

Na proposta 1.1, o programa Nossa Cidade Mais Limpa busca recuperar os locais com ações que promovam melhorias estéticas na cidade, realizando retiradas de cartazes, pinturas de pichações, capinação e jardinagem. Diante das pesquisas, identificaram-se atuações do programa na cidade de Natal, e as articulações efetivadas foram entre a Companhia de Serviços Urbanos de Natal e a Secretaria Municipal de Mobilidade Urbana (STTU).

A proposta 2 refere-se ao Programa de Aceleração do Crescimento (PAC) coordenado pelo Ministério do Planejamento, que em 2013 autorizou a criação de uma linha destinada exclusivamente aos sítios históricos urbanos protegidos pelo Instituto do Patrimônio Histórico e Artístico Nacional (IPHAN). Em Natal, este programa investiu em processos de reabilitação, restauração e requalificação dos centros históricos, praças e edifícios de uso público (BRASIL, 2015). 
A proposta 3, que trata da recuperação dos banheiros públicos da Orla de Ponta Negra, recomenda ações de reparação aos danos causados pelo vandalismo. E a Secretaria de Serviços Urbanos (SENSUR) iniciou o processo de privatização dos banheiros públicos da Orla de Ponta Negra, um processo que já foi realizado em Recife/PE e no Rio de Janeiro/RJ.

Em síntese, diante do levantamento dos programas/planos/projetos da cidade do Natal, nota-se que as políticas de revitalização concentram-se nas seguintes secretarias: Serviços Urbanos (SENSUR), a Secretaria de Meio Ambiente e Urbanismo (SEMURB), e pelo PAC Cidades Históricas, sendo este último coordenado pelo Ministério de Planejamento e pelo Ministério da Cultura.

Já a cidade de Recife ocupa posição central no litoral do Nordeste brasileiro e encontra-se a aproximadamente $800 \mathrm{~km}$ das metrópoles regionais de Salvador e Fortaleza, tem clima tropical-úmido e os ambientes naturais são compostos por praias, rios, mangues, matas e mananciais. A urbanização da cidade deu-se a partir do bairro do Recife, em meio a uma estrutura radiocêntrica, em forma de estrela e com cinco direções (norte, sul, sudeste oeste e noroeste), resultante da ligação entre seu núcleo primitivo e os antigos engenhos. Salienta-se que com crescimento da cidade em direção a bairros periféricos e municípios vizinhos desenvolveramse novas centralidades (RECIFE PREFEITURA DA CIDADE, 2019).

A política de gestão urbana da cidade é regulada conforme o Plano Diretor da cidade do Recife/PE (Lei no 17.511/2008) documento que explicita, dentre os princípios fundamentais (art. $2^{\circ}$ ) da política do município do Recife, a função social da cidade que corresponde ao direito de todos ao acesso à terra urbana, à moradia, ao saneamento ambiental, ao transporte, à saúde, à educação, à assistência pública, ao lazer, ao trabalho e renda, bem como a espaços públicos, equipamentos, infraestrutura e serviços urbano, ao patrimônio ambiental e histórico-cultural da cidade (BRASIL, 2008).

Logo, considerando o levantamento realizado dos programas, projetos e/ ou ações (Quadro 2) feitos para fins de traçar um delineamento sobre o que está sendo desenvolvido e a intersetorialidade existente entre os órgãos que compõe a administração pública municipal, inicialmente será esclarecido o que, de forma especifica, está descrito no plano diretor quanto aos dispostos, em particular, sobre o turismo, item referente a política de desenvolvimento econômico, e acerca da política de esporte, lazer e recreação.

Com relação ao turismo (Seção II, p. 8), a política municipal tem dentre os seus objetivos (art. 14), promover programas, projetos e ações turísticas com a dinâmica das atividades sociais, econômicas, culturais e de lazer, realizadas no município e na região metropolitana de Recife (Parágrafo III). E quanto à política 
municipal de esporte, lazer e recreação, observam-se as seguintes diretrizes: consolidação do esporte do lazer e da recreação como direito dos cidadãos e dever do estado; garantia do acesso universal e integral às práticas esportivas promovendo o bem-estar e a melhoria da qualidade de vida dos cidadãos; implementação de programas estruturadores de esporte e lazer voltados ao fortalecimento da noção da cidadania; identificação de áreas que necessitam de equipamentos de esporte e lazer mediante elaboração de diagnóstico e metas de atendimento (BRASIL, 2008, p. 17). Visualizam-se no Quadro 2 as políticas públicas e as ações da cidade do Recife.

Quadro 2 - Políticas públicas de revitalização urbana de Recife/PE

\begin{tabular}{|c|c|c|c|}
\hline $\begin{array}{l}\text { Secreta- } \\
\text { ria/orgão }\end{array}$ & $\begin{array}{l}\text { Plano } \\
\text { Programa } \\
\text { Projeto }\end{array}$ & Objetivo & Ação/situação \\
\hline \multirow{5}{*}{ 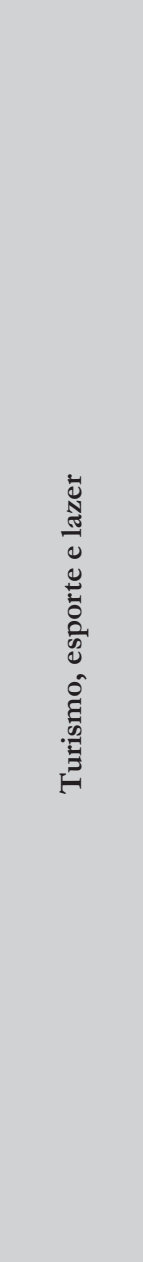 } & $\begin{array}{l}\text { Projeto de Revita- } \\
\text { lização do Cais da } \\
\text { Aurora: compreen- } \\
\text { de o complexo } \\
\text { esportivo e de lazer } \\
\text { (Proposta 1) }\end{array}$ & $\begin{array}{l}\text { Construção de um Com- } \\
\text { plexo Esportivo e de La- } \\
\text { zer. }\end{array}$ & $\begin{array}{l}\text { Construção de uma quadra } \\
\text { poliesportiva, pista de cami- } \\
\text { nhada e ciclismo, equipamento } \\
\text { de ginástica, quiosque, parque } \\
\text { infantil, arena de esportes radi- } \\
\text { cais; teatro de arena. } \\
\text { Finalizado }\end{array}$ \\
\hline & $\begin{array}{l}\text { Projeto de Revitali- } \\
\text { zação Turística do } \\
\text { Bairro de Recife } \\
\text { (Proposta 2) }\end{array}$ & $\begin{array}{l}1 \text { - Recuperar o bairro } \\
\text { de Recife, de maneira a } \\
\text { atender os habitantes das } \\
\text { favelas, trabalhadores do } \\
\text { porto e prostitutas que } \\
\text { habitavam o bairro; } 2 \text { - } \\
\text { Implantou-se o projeto } \\
\text { cores da cidade. }\end{array}$ & $\begin{array}{l}1 \text { - Recuperação de espaços } \\
\text { públicos como ruas, calçadas, } \\
\text { iluminação, esgoto, dentre } \\
\text { outras. } 2 \text { - Recuperava-se as } \\
\text { fachadas da casa com tinta for- } \\
\text { necida por empresas interna- } \\
\text { cionais; restauração de prédios } \\
\text { desapropriados. } \\
\text { Finalizado }\end{array}$ \\
\hline & $\begin{array}{l}\text { Projeto de Revita- } \\
\text { lização Complexo } \\
\text { Turístico-Cultural } \\
\text { Recife/Olinda } \\
\text { (Proposta 3) }\end{array}$ & $\begin{array}{l}\text { Gerar renda e inclusão } \\
\text { sócio-territorial de popu- } \\
\text { lações carentes. }\end{array}$ & $\begin{array}{l}\text { Revitalização de bairro novo e } \\
\text { trecho de casa caiada; Urbani- } \\
\text { zação de trecho de Casa Caia- } \\
\text { da e Rio Doce. } \\
\text { Finalizado/novos projetos }\end{array}$ \\
\hline & $\begin{array}{l}\text { Projeto Rede Física } \\
\text { Municipal }\end{array}$ & $\begin{array}{l}\text { Prevê a recuperação, } \\
\text { construção e gestão de } \\
\text { equipamentos da cidade, } \\
\text { priorizando os espaços da } \\
\text { periferia, com potenciais } \\
\text { de multifuncionalidade e } \\
\text { democráticos. }\end{array}$ & $\begin{array}{l}\text { Oportunizar espaços para o } \\
\text { ensino e o lazer aos alunos da } \\
\text { rede municipal. }\end{array}$ \\
\hline & $\begin{array}{l}\text { Centro de Informa- } \\
\text { ções Turísticas }\end{array}$ & $\begin{array}{l}\text { Postos de atendimento ao } \\
\text { visitante/turista. }\end{array}$ & $\begin{array}{l}\text { Informações sobre a cidade e } \\
\text { acerca das atividades que po- } \\
\text { dem ser realizadas na cidade; } \\
9 \text { CATs. }\end{array}$ \\
\hline
\end{tabular}




\begin{tabular}{|c|c|c|c|}
\hline & $\begin{array}{l}\text { Roteiros por tempo } \\
\text { de duração e circui- } \\
\text { tos são oferecidos } \\
\text { como atrativos para } \\
\text { os visitantes/turis- } \\
\text { tas }\end{array}$ & $\begin{array}{l}\text { Conhecer por meio de ro- } \\
\text { teiros um pouco da histó- } \\
\text { ria do lugar. }\end{array}$ & Atrativos e passeios. \\
\hline & $\begin{array}{l}\text { Programa Círcu- } \\
\text { los Populares de } \\
\text { Esporte e Lazer } \\
\text { (CPEL) - } 2001\end{array}$ & $\begin{array}{l}\text { O objetivo é implantar } \\
\text { nas comunidades de baixa } \\
\text { renda da cidade, círculos } \\
\text { de convivência social. }\end{array}$ & $\begin{array}{l}\text { Encontra-se projetos de fute- } \\
\text { bol participativo, círculos do } \\
\text { esporte, do lazer, de juventude; } \\
\text { animação de parque e praças e } \\
\text { esporte do mangue. }\end{array}$ \\
\hline & $\begin{array}{l}\text { Academia Recife; } \\
\text { Parques e Praças; } \\
\text { praias; ciclofaixa de } \\
\text { turismo e lazer }\end{array}$ & $\begin{array}{l}\text { Jardim Botânico de Recife } \\
\text { (1); } \\
\text { Sitio Trindade (2); Recife } \\
\text { Antigo de Coração (3); } \\
\text { Recife tem uma das praias } \\
\text { mais bonitas do Brasil, a } \\
\text { praia de Boa Viagem (4). }\end{array}$ & $\begin{array}{l}\text { (1) É um espaço ambiental } \\
\text { que agrega lazer, ciência } \\
\text { e educação, totalmente } \\
\text { estruturado para receber } \\
\text { turistas e moradores. (2) É } \\
\text { utilizado como espaço para } \\
\text { a realização de atividades } \\
\text { culturais. (3) O bairro do Recife } \\
\text { se tornou um grande parque a } \\
\text { céu aberto aos domingos. (4) } \\
\text { O calçadão de Boa Viagem } \\
\text { tem quadras esportivas e } \\
\text { quiosques, e disponibiliza toda } \\
\text { estrutura de hotéis e serviços. }\end{array}$ \\
\hline 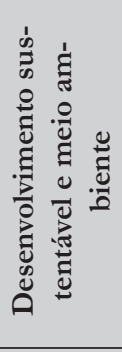 & $\begin{array}{l}\text { Projeto de Revi- } \\
\text { talização de Áreas } \\
\text { Verdes (PRAV) }\end{array}$ & $\begin{array}{l}\text { Sua finalidade é recuperar } \\
\text { ou plantar vegetação em } \\
\text { local a ser definido em } \\
\text { conjunto pelo particular e } \\
\text { pelo poder público. } \\
\text { Etapas: aprovação da área; } \\
\text { aprovação do projeto; } \\
\text { e atestar a execução do } \\
\text { PRAV. }\end{array}$ & $\begin{array}{l}\text { Serviços de plantio e de ma- } \\
\text { nutenção da arborização no } \\
\text { ambiente natural e construído; } \\
\text { guiados pelo manual de arbori- } \\
\text { zação urbana. } \\
\text { Em andamento. }\end{array}$ \\
\hline 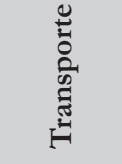 & $\begin{array}{l}\text { Ciclofaixa de turis- } \\
\text { mo e lazer }\end{array}$ & $\begin{array}{l}\text { São percursos implanta- } \\
\text { dos temporariamente. }\end{array}$ & $\begin{array}{l}\text { Funcionam aos domingos e } \\
\text { feriados. }\end{array}$ \\
\hline कू & $\begin{array}{l}\text { Programa para pro- } \\
\text { mover a saúde e a } \\
\text { cidadania em diver- } \\
\text { sas comunidades }\end{array}$ & $\begin{array}{l}\text { Reformar tradicionais } \\
\text { áreas verdes potenciali- } \\
\text { zando o local com equi- } \\
\text { pamentos para a prática } \\
\text { de esportes (academias da } \\
\text { cidade). }\end{array}$ & $\begin{array}{l}\text { Aulas de ginástica e dança; } \\
\text { passeios temáticos; corrida e } \\
\text { caminhada, práticas corporais } \\
\text { para todos os ciclos da vida } \\
\text { (ginástica, jogos, dança, espor- } \\
\text { tes, luta, outros) etc. }\end{array}$ \\
\hline
\end{tabular}




\begin{tabular}{|l|l|l|l|}
\hline \multirow{2}{*}{} & $\begin{array}{l}\text { Plano Centro Ci- } \\
\text { dadão }\end{array}$ & $\begin{array}{l}\text { Buscar soluções para o } \\
\text { planejamento urbano na } \\
\text { área e oferecer um estudo } \\
\text { de referência para a con- } \\
\text { cepção de diretrizes urba- } \\
\text { nísticas. }\end{array}$ & $\begin{array}{l}\text { Analisa as necessidades urba- } \\
\text { nísticas de espaços públicos e } \\
\text { privados como fonte de his- } \\
\text { tória. }\end{array}$ \\
\cline { 2 - 5 } & $\begin{array}{l}\text { Plano específico } \\
\text { para o Cais de San- } \\
\text { ta Rita, Cais José } \\
\text { Estelita e Cabanga }\end{array}$ & $\begin{array}{l}\text { Revitalização e requalifica- } \\
\text { ção de áreas centrais. }\end{array}$ & $\begin{array}{l}\text { Lei 18.138/2015: princípios de } \\
\text { qualidade urbana e ambiental. } \\
\text { Instrumento necessário para } \\
\text { o desafio da revitalização e re- } \\
\text { qualificação de uma área cen- } \\
\text { tral. }\end{array}$ \\
\hline
\end{tabular}

Fonte: Dados da pesquisa (2017)

Assim como na descrição do quadro anterior, selecionaram-se apenas algumas das propostas para serem apresentadas a seguir. A proposta 1 trata do Projeto de Revitalização do Cais da Aurora: compreende o complexo esportivo e de lazer. O documento analisado evidencia que durante a realização do projeto surgiram obstáculos e geraram-se conflitos diante da experiência de relação de poder entre o setor público e a participação popular em vários níveis e etapas de construção da política.

Tendo em vista os documentos, observou-se que após a ocorrência de debates entre atores do mercado, o engenheiro responsável pela obra, os representantes da Empresa de Urbanização do Recife (URB) e da Diretoria Geral de Esportes (DGE), os moradores do entorno e o Estado, destaca-se que, em 2004, a ordem de serviço para revitalização do Cais foi assinada (LOUREIRO; SOUZA, 2006). Ainda no mesmo ano foi inaugurada a primeira etapa da revitalização do Cais e em 2005 foi entregue à população a segunda etapa da revitalização do cais da Aurora. Já a terceira etapa foi marcada pelo diálogo entre prefeitura e sociedade para tratar sobre a organização democrática de utilização dos equipamentos e do espaço em si.

Quanto à Proposta 2, sobre o Projeto de Revitalização Turística do Bairro de Recife, nas últimas décadas do século XX, investiu-se em ações de renovação urbana do referido local, e esta revitalização gerou questões necessárias de serem debatidas sobre o aspecto do planejamento urbano. Este projeto foi proposto em 1992, coordenado pela agência de desenvolvimento da Ilha do Recife, e a reforma melhorava as condições operacionais do comércio exportador/importador e delineava uma nova imagem para a cidade. A proposta de recuperação pretendia beneficiar atores locais de baixa renda, fazendo com que os principais atores econômicos locais se afastassem do projeto (BOAVENTURA et al., 2012). 
Após a realização das duas primeiras etapas do projeto, não houve grandes investimentos no bairro, uma vez que o projeto havia adquirido pouca credibilidade. Assim, seguido deste plano, outros projetos foram lançados, demarcando a passagem do Recife Antigo para o Novo Recife.

Por fim, a proposta 3, que aborda o Projeto de Revitalização Complexo Turístico-Cultural Recife/Olinda, foi constituída por duas etapas, marcadas por obras de revitalização e urbanização. Quanto aos atores envolvidos, destacam-se a Secretaria de Obras, a Secretaria de Transporte, Controle Urbano e Ambiental, a Secretaria de Turismo, Desenvolvimento Econômico e tecnológico, Prefeitura de Cidade Olinda, Ministério do Turismo e o Governo de Pernambuco (OLINDA PREFEITURA MUNICIPAL, 2019).

Considerando esta breve descrição acerca de algumas políticas ou ações apresentadas que esclarecem quem são os envolvidos nas atividades propostas, a seguir, apresenta-se o delineamento dos aspectos relacionais entre o Projeto de Reurbanização da Praça Largo Djalma Maranhão, Natal/RN, e o Projeto de Revitalização Turística do Bairro de Recife, Recife/PE.

\section{ASPECTOS RELACIONAIS ENTRE AS POLÍTICAS PÚBLICAS DE REVITALIZAÇÃO}

A partir da pesquisa identificaram-se uma quantidade de 8 entre políticas, planos, projetos ou ações direcionados para uma melhor gestão urbana da cidade de Natal, e foram apontadas 13 propostas destinadas à cidade do Recife. Percebese que ambas as cidades estão desenvolvendo políticas e ações destinadas a promover um ordenamento e revitalização dos espaços urbanos objetivando uma melhoria e recuperação desses espaços, conforme os Quadros 1 e 2. Outro aspecto semelhante refere-se ao planejamento dos projetos, uma vez que se verificou o envolvimento de diferentes secretarias no processo de elaboração das propostas, demonstrando a busca pelo desenvolvimento de um trabalho integrado e participativo.

Diante dos dados apresentados, foram analisados o Projeto de Reurbanização da Praça Largo Djalma Maranhão de Natal (Proposta 4), Quadro 1; e o Projeto de Revitalização Turística do Bairro de Recife (Proposta 2), Quadro 2, a fim de traçar uma discussão mais densa, delineando os aspectos relacionais entre estas políticas, conforme Quadro 3 a seguir. Justifica-se que são propostas de natureza aparentemente semelhantes, cuja intenção da análise é traçar um paralelo para identificar as similitudes e as diferenças existentes. A escolha pela investigação destes projetos se deu de forma aleatória, levando em consideração que ambos possuem em seus títulos os termos revitalização ou reurbanização. 
Quadro 3 - Projeto de reurbanização e projeto de revitalização: aspectos relacionais e divergentes

\begin{tabular}{|l|l|}
\multicolumn{2}{|c|}{ Proposta 4 (Quadro 1) } \\
\begin{tabular}{|l|l|} 
Criar condições para mais lazer e qualidade \\
de vida na cidade.
\end{tabular} & $\begin{array}{l}\text { Mudança de um projeto habitacional para } \\
\text { um projeto turístico. }\end{array}$ \\
\hline Inserir novos serviços nas praças. & $\begin{array}{l}\text { Exclusão de proprietários de bares do } \\
\text { projeto, para dar um novo sentido ao } \\
\text { espaço. }\end{array}$ \\
\hline Diminuir a ação de vândalos. & $\begin{array}{l}\text { Segregação social por meio da prática de } \\
\text { preços mais altos. }\end{array}$ \\
\hline $\begin{array}{l}\text { Instalar academias ao ar livre para a a } \\
\text { população. }\end{array}$ & $\begin{array}{l}\text { Projeto vinculado a uma gestão financeira } \\
\text { de eventos para atração de sujeitos aos } \\
\text { estabelecimentos. }\end{array}$ \\
\hline $\begin{array}{l}\text { Valorizar espaços tradicionais e tornar a a } \\
\text { área de abrangência da praça um ponto de } \\
\text { atração turística da cidade. }\end{array}$ & $\begin{array}{l}\text { Ausência de elementos que valorizem as } \\
\text { tradições locais. }\end{array}$ \\
\hline
\end{tabular}

Fonte: Dados da pesquisa (2017).

O Projeto de Reurbanização da Praça Largo Djalma Maranhão de Natal refere-se a uma ação de reforma, cuja proposta é dar novo uso e sentido a um espaço já existente e de domínio público. Quanto ao Projeto de Revitalização Turística do Bairro de Recife, tentou-se fazer com que um espaço não frequentado e em desuso, pudesse ser inserido, partindo de uma nova conjuntura, no cotidiano das pessoas.

Pode-se observar que a proposta 4, especificada no Quadro 3, está relacionada à busca da prefeitura municipal em recuperar o passeio nas praças, fazer reforma de acessibilidade, recuperação de bancos, pinturas, colocação de iluminação e paisagismo. A secretaria responsável por esse tipo de ação é a Secretaria Municipal de Serviços Urbanos (SEMSUR), focada na construção, manutenção e recuperação de praças e logradouros da cidade de Natal (PREFEITURA DO NATAL, 2015).

O interessante da proposta é ver que o foco não está relacionado aos turistas em si, uma vez que eles também fazem uso desse tipo de espaço, mas à comunidade local. Pensou-se em promover lazer e proporcionar melhor qualidade de vida, primeiramente, aos residentes. Logo, destaca-se que estando o espaço adequado para receber os residentes, esse estará apropriado, consequentemente, para aqueles que visitam a cidade.

O quarto item da Proposta 4, no Quadro 3, que se refere a inserir novos serviços na localidade, indica uma forma de oportunizar a geração de emprego 
e renda para a comunidade local, assim como possibilitar um novo uso para o referido espaço urbano, dando ao mesmo tempo um diferente sentido ao lugar. A instalação de infraestrutura para criação de novos hábitos, como é o caso da implementação de academias de rua, permite que haja uma maior socialização entre as pessoas e um estímulo a promoção da saúde.

Para Ribeiro (2008), "é preciso perceber os sentidos que o espaço ganha, conforme o tempo e o lugar. A praça pública se confunde com a própria origem da cidade". A ausência de utilidade e abandono de determinados espaços pode gerar uma marginalização do lugar e afastamento das pessoas.

A cidade do Natal vem sofrendo com o aumento da marginalização e da criminalização, em virtude, muitas vezes, de espaços inutilizados que acabam sendo foco para realização de condutas indevidas. Ressalta-se, então, que tais acontecimentos alteram a dinâmica local, especialmente, no que se refere a visitação do lugar por parte de turistas, o que demonstra a importância de políticas públicas voltadas para revitalização de espaços.

A proposta 2, Quadro 3, teve como intuito integrar o bairro do Recife (espaço geográfico) ao território da grande Recife. Considerando a imagem do bairro como marginalizado, procurou-se, por meio do projeto de revitalização turística, reconstruir a imagem antiga do bairro para um bairro de eventos e comemorações.

Para tanto, a proposta incluía a criação de áreas de interação cultural local entre a comunidade local, do grande Recife, turistas e visitantes. Vale salientar que a Secretaria de Turismo da cidade ficou como responsável pelo projeto e, portanto, o foco da proposta foi reinventar o lugar como um local para realização de eventos e para atração de potenciais visitantes.

Sobre os pontos assinalados no Quadro 3, referentes a proposta 2, elucida-se que não é um trabalho simples promover uma mudança de ordenação de bairros e uma integração entre os atores locais envolvidos, especialmente por envolver pessoas e suas relações de valor, cultura, estilos de vida, modo de sobrevivência, entre outros. Toda mudança requer tempo e um período de adaptação, divergências existem, e discussões sobre a melhor forma de se estabelecer uma nova proposta são necessárias. É importante considerar o ponto de vista dos envolvidos direta e/ou indiretamente nos projetos, como a comunidade, atores privados, por exemplo, e demonstrar de que forma tais grupos serão inseridos nesse processo.

Caso o processo de implementação de um projeto de revitalização, como o discutido em questão, seja realizado de "cima para bairro", vindo como ordem de implementação do governo ausente de planejamento participativo, consequências como o aumento dos índices de migração dos moradores locais, 
vandalismo e criminalidade podem aumentar e fazer com que haja um efeito contrário ao da proposta. Como se trata da mudança de uso de um lugar para atrair turistas, cabe aos incentivadores do projeto de revitalização verificarem a existência de um potencial de aceitação por parte da população autóctone quanto a receber pessoas vindas de outros lugares e estarem interessadas no aumento do fluxo de pessoas cada vez maior naquele espaço.

A fuga aos preceitos do planejamento participativo e do turismo sustentável tendem a ocasionar o efeito "rebote" do turismo, pois apesar das cidades passarem a se beneficiar com os lucros financeiros advindos da atividade turística, as populações residentes acabam se afastando destes espaços urbanos, por terem sido excluídas do processo planejamento (CANCLINI, 1994; ABREU; CHAGAS, 2009).

Além disso, é relevante certificar-se como a comunidade local que possui estabelecimentos comerciais nos espaços contemplados pelas políticas vai ser afetada, tendo em vista que a reorganização do lugar acaba por modificar sua dinâmica de vida positiva e/ou negativamente. Nesse caso, é preciso refletir, orientar, capacitar, oportunizar e/ou melhorar o que já existe de modo a considerar o cotidiano e hábitos daqueles que ali se encontram.

É inadequado impor projetos para uma comunidade através do poder, sem levar em consideração os grupos existentes e que compartilham da dinâmica do lugar, uma vez que o papel do ator público é justamente garantir os direitos dos cidadãos e, portanto, de forma sustentável oferecer modos de melhorar a qualidade de vida das pessoas (SANTOS; CASTROGIOVANNI, 2010). Em suma, entende-se que é preciso pensar na inserção dos sujeitos, sejam parte da comunidade ou proprietários de estabelecimentos na nova reconfiguração apresentada, de modo a equilibrar o uso do referido espaço pelas pessoas da localidade e, também, pelos potenciais turistas.

\section{CONCLUSÃO}

A partir deste estudo, observou-se que as políticas de revitalização das cidades de Natal e Recife encontram-se instituídas por diferentes secretarias de uma administração pública, mas que existe a tentativa de realizar um trabalho de forma intersetorial, levando em consideração diferentes necessidades de uma localidade. Contudo, essa questão conduz para possibilidade de realização de um estudo que identifique o nível de integração dos diferentes setores envolvidos no tocante à execução destas propostas de revitalização/recuperação. 
Verificou-se que, em particular nas propostas de Recife, a tentativa de envolver a comunidade local no processo de decisão para a elaboração das políticas e para fins de democratização do uso dos espaços. Este fato demonstra interesse em reconhecer as necessidades dos diferentes atores locais.

Na cidade de Natal é possível visualizar uma preocupação por parte das secretarias públicas voltadas para a elaboração de programas que proporcionem uma melhora na qualidade ambiental e paisagística do município, bem como programas relacionados à revitalização dos espaços urbanos especialmente na orla marítima urbana. Além disso, destaca-se também o interesse das secretarias em trabalharem de forma integrada para a elaboração e realização dos programas.

E, por fim, outra questão a ser destacada é o fato de algumas políticas requererem investimentos privados para sua efetivação, mas que em virtude do abandono e deterioração dos locais contemplados pelas políticas, onde a maior circulação e/ou habitação corresponde a pessoas de baixa renda, acabam não sendo uma opção de investimentos para empresários do setor privado, impossibilitando as parcerias público-privadas necessárias.

É importante observar que a presente pesquisa é resultado de uma análise de documentos oficiais, que refletem, pelo menos parcialmente, a postura adotada pelas instituições públicas governamentais responsáveis pela gestão das cidades de Natal e Recife. No entanto, para que tais dados sejam confirmados ou negados, torna-se necessário contrastá-los empiricamente. Portanto, a partir deste estudo abrem-se novos caminhos de investigação para pesquisas futuras.

\section{REFERÊNCIAS}

ABREU, R.; CHAGAS, M. (org.). Memória e patrimônio: ensaios contemporâneos. 2. ed. Rio de Janeiro: Lamparina, 2009.

AMARAL, S. C. Políticas públicas, lazer e sustentabilidade: desafios e perspectivas. In: BAHIA, M. C. (org.). Novas leituras do lazer contemporâneo. Belém: NAEA, 2018. p. 91-104.

BAHIA, M. C.; FIGUEIREDO, S. L. Políticas públicas de lazer em Belém e abordagens intersetoriais. In: AZEVEDO, F. F. et al. (org.). Turismo em foco. Belém: NAEA, 2013, p. 248-268.

BARRETTO, M. Revitalização urbana, lazer e turismo. Rosa dos Ventos: Turismo e Hospotalidade, Caxias do Sul, n. 5, v. 4, p. 592-601, out./dez. 2013. Disponível em: http://www.ucs.br/etc/revistas/index.php/rosadosventos/ article/view/2127. Acesso em: 02 jun. 2017. 
BEZERRA, A. M. M.; CHAVES, C. R. C. Revitalização urbana: entendendo o processo de requalificação da paisagem. Revista do Centro de Estudos em Desenvolvimento Sustentável, São Luís, n. 1, p. 1-16, ago./dez. 2014. Disponível em: http://www.undb.edu.br/publicacoes/arquivos/rev._ceds_n.1_-_ revitaliza $\% \mathrm{C} 3 \% \mathrm{~A} 7 \% \mathrm{C} 3 \% \mathrm{~A} 30 \_u r b a n a \_$entendendo_o_processo_de_requalifica $\%$ C3\%A7\%C3\%A3o_da_paisagem_-_aline_bezerra.pdf. Acesso em: 04 jun. 2017. BOAVENTURA, C. et al. Plano de reabilitação do Bairro do Recife. Campinas: UNIP, 2012. 14 p. Disponível em: https:/ pt.slideshare.net/pamelagpa/trabalhosobre-recife. Acesso em: 02 nov. 2019.

BORGES, A. L. M., FERREIRA, L. D. de O.; NÓBREGA, W. R. de M. Políticas públicas de revitalização urbana: uma abordagem no turismo e lazer da cidade de Natal/RN. In: COLÓQUIO NACIONAL SOBRE CIDADES LITORÂNEAS E TURISMO, 1., 2017, Recife. Anais [...]. Recife: UFPE, 2017. p. 1-14. Disponível em: http://cilitur.com.br/cilitur/arquivos/tematica2/BORGES-AL-M-FERREIRA-L-D-O-NOBREGA-W-R-M.pdf. Acesso em: 02 nov. 2019.

BRASIL. Constituição da República Federativa do Brasil. Dispõe sobre as emendas constitucionais de Revisão. Brasília, DF: Presidência da República, 1988. Disponível em: http://www.planalto.gov.br/ccivil_03/constituicao/ constituicaocompilado.htm. Acesso em: 01 jun. 2017.

BRASIL. Lei complementar $\mathbf{n}^{\circ} 82$, de 21 de junho de 2007. Dispõe sobre o Plano Diretor de Natal e dá outras providências. Natal: Prefeitura Municipal de Natal, 2007. Disponível em: https://leismunicipais.com.br/a/rn/n/natal/leicomplementar/2007/8/82/lei-complementar-n-82-2007-dispoe-sobre-o-planodiretor-de-natal-e-da-outras-providencias. Acesso em: 02 nov. 2019.

BRASIL. Lei $\mathbf{N}^{\mathbf{0}}$ 17.511, de 29 de dezembro de 2008. Dispões sobre a política urbana de Recife, 2008. Disponível em: https://licenciamento.recife. pe.gov.br/sites/default/ files / 2008\%20-\%20Plano\%20Diretor\%20Lei\%20 n\%C2\%BA\%2017511.08.pdf. Acesso em: 02 nov. 2019.

BRASIL. Ministério do Planejamento. PAC cidades históricas Natal RN. Brasília, DF, 2015. Disponível em: https://www.natal.rn.gov.br/coopere/ paginas/File/09_-_APRESENTACAO_IPHAN_-_LITANY_EUFRASIO.pdf. Acesso em: 02 nov. 2019.

CANCLINI, N. G. O patrimônio cultural e a construção imaginária do nacional. Revista do Patrimônio Histórico e Artístico Nacional, Brasília, n. 23, p. 94-115, 1994. 
CASTRO, A. T.; FIGUEIREDO, S. L. Turismo, políticas públicas e espaços públicos urbanos: a Estação das Docas em Belém, Pará. In: AZEVEDO, F. F. et al. (org.). Turismo em foco. Belém: NAEA, 2013. p. 189-202.

DUMAZEDIER, J. A revolução cultural do tempo livre. São Paulo: Studio, 1994.

FIGUEIREDO, S. L. Viagens viajantes. São Paulo: Annablume, 2009.

FLICK, U. Introdução à pesquisa qualitativa. 3. ed. Porto Alegre: Artmed, 2009.

PREFEITURA DO NATAL. Prefeitura realiza amplo trabalho de revitalização nas praças de Natal. Natal, 30 set. 2015 In: G1. Disponível em: http://g1.globo.com/rn/rio-grande-do-norte/especial-publicitario/prefeiturado-natal/natal-a-nossa-cidade/noticia/2015/09/prefeitura-realiza-amplotrabalho-de-revitalizacao-das-pracas-de-natal.html. Acesso em: 02 nov. 2019.

GODOY, A. S. Pesquisa qualitativa: tipos fundamentais. Revista de Administração de Empresas, São Paulo, v. 35, n. 3, p. 20-29, maio/jun. 1995. Disponível em: http://bibliotecadigital.fgv.br/ojs/index.php/rae/article/ view/38200/36944. Acesso em: 03 jun. 2017.

HARVEY, D. Condição pós-moderna: uma pesquisa sobre as origens da mudança cultural. São Paulo: Loyola, 2005.

INSTITUTO BRASILEIRO DE GEOGRAFIA E ESTATÍSTICA. Cidades. Rio de Janeiro: IBGE, 2016. Disponível em: http:/ / cod.ibge.gov.br/G33. Acesso em 09 ago. 2017.

LEITE, R. P. Contra usos da cidade: lugares e espaço público na experiência urbana contemporânea. Campinas: UNICAMP, 2004. Disponível em: http://revistas.ucg. br/index.php/habitus/article/download/221/175. Acesso em: 09 jun. 2017.

LOUREIRO, J. de A.; SOUZA, V. R. F. de P. Política de lazer e o espaço urbano: a experiência da revitalização do Cais da Aurora em Recife-PE. Motrivivência, Florianópolis, Ano XVIII, n. 26, p. 155-167, 2006. Disponível em: https:/ / periodicos. ufsc.br/index.php/motrivivencia/article/view/686. Acesso em: 05 jun. 2017.

MACCANNEL, D. E1 turista, una nueva teoría de la clase ociosa. Barcelona: Ed. Melusina, 2003.

MARCELLINO, N. C. Lazer e sociedade. Campinas: Alínea, 2008.

MORAGAS, R. A.; MORAGAS, W. M. Revitalização dos espaços públicos de lazer: Exemplo do Parque das Andorinhas - Presidente Prudente- 
SP/Brasil. Observatório Geográfico da América Latina, n. 14, 2007. Disponível em: http://observatoriogeograficoamericalatina.org.mx/egal12/ Geografiasocioeconomica/Geografiaurbana/270.pdf. Acesso em: 04 jun. 2017.

NATAL. Lei complementar $\mathbf{N}^{\mathbf{0}}$ 82, de 21 de junho de 2007. Dispõe sobre o Plano Diretor de Natal e dá outras providências. Natal: Prefeitura Municipal de Natal, 2007. Disponível em: https://leismunicipais.com.br/a/rn/n/natal/leicomplementar/2007/8/82/lei-complementar-n-82-2007-dispoe-sobre-o-planodiretor-de-natal-e-da-outras-providencias. Acesso em: 02 nov. 2019.

NÓBREGA, W. R. de M. Participação popular e as políticas públicas de turismo na Amazônia: o PROECOTUR no distrito de Mosqueiro, Belém PA. 2006. 183 f Dissertação (Mestrado em Cultura e Turismo) - Universidade Estadual de Santa Cruz, Santa Cruz; Universidade Federal da Bahia, Ilhéus, 2006.

NÓBREGA, W. R. de M. Turismo, desenvolvimento, e políticas públicas: limites e avanços no Estado do Pará. In: AZEVEDO, F. F. et al. (org.). Turismo em foco. Belém: NAEA, 2013, p. 92-115.

OLINDA PREFEITURA MUNICIPAL. Programas e ações. Olinda: Prefeitura Municipal, 2019. Disponível em: http://www.olinda.pe.gov.br/programas-eacoes/revitalizacao-da-orla\#.WTquGmjyvIU. Acesso em: 02 nov. 2019.

PRONOVOST, G. Introdução à sociologia do lazer. São Paulo: Editora Senac, 2011.

RECIFE. Lei No 17.511, de 29 de dezembro de 2008. Promove a revisão do Plano Diretor do Município do Recife. Recife: Prefeitura Municipal, 2008. Disponível em: https:/ /licenciamento.recife.pe.gov.br/sites/default/files/2008\%20-\%20Plano\%20 Diretor\%20Lei\%20n\%C2\%BA\%2017511.08.pdf. Acesso em: 02 nov. 2019.

RECIFE PREFEITURA DA CIDADE. Aspectos urbanísticos e ambientais do Recife. Recife: Prefeitura Municipal, 2019. Disponível em: http:// www2.recife.pe.gov.br/servico/aspectos-urbanisticos-e-ambientais-dorecife?op $=$ NTI4Mw $==$. Acesso em: 02 nov. 2019.

RIBEIRO, I. P. Z. As praças de cultura no governo de Djalma Maranhão (1960 - 1964). 2008. 123 f. Dissertação (Mestrado em História) - Programa de Pós-Graduação em História, Universidade Federal do Rio Grande do Norte, Natal, 2008. Disponível em: http://livros01.livrosgratis.com.br/cp064648.pdf. Acesso em: 20 jul. 2017. 
RICHARDSON, R. J. Pesquisa social: métodos e técnicas. 3. ed. São Paulo: Atlas, 1999.

SANTOS, R. S.; CASTROGIOVANNI, A. C. O Plano de Revitalização do Bairro de Recife trouxe uma nova ordenação espacial ou não? In: SEMINÁRIO DE PESQUISA EM TURISMO DO MERCOSUL, 6., 2010, Caxias do Sul. Anais [...]. Caxias do Sul: UCS, 2010. p. 1-17. Disponível em: http://www.ucs.br/ ucs/tplSeminTur2010/eventos/seminario_de_pesquisa_semintur/anais/gt07/ arquivos $/ 07 / \mathrm{O} \% 20 \mathrm{Plano} \% 20 \mathrm{de} \% 20$ Revitalizacao $\% 20 \mathrm{do} \% 20 \mathrm{Bairro} \% 20 \mathrm{do} \% 20$ Recife\%20Trouxe\%20uma\%20Nova\%20Ordenacao.pdf. Acesso em 05 jun. 2017.

SECCHI, L. Políticas públicas: conceitos, esquemas de análise, casos práticos. São Paulo: Cengage Learning, 2014.

SEMURB. Secretaria de Mobilidade Urbana. Plano de Ordenamento, Gestão e Fiscalização. Natal, 2017. Disponível em: http://natal.rn.gov.br/noticia/ntc25623.html. Acesso em: 10 jun. 2017.

SILVA, E. A. Lazer nos espaços urbanos. Revista Eletrônica AGB-TL, Três Lagoas, n. 1, p. 54-69, dez./maio 2004.

SILVA, J. M. Políticas públicas como instrumento de inclusão social. Revista da Faculdade de Direito da UFG, Goiânia, v. 35, n. 1, p. 160-185, jan./jun. 2011.

SOUZA, C. Políticas públicas: conceitos, tipologias e sub-área. São Paulo: Fundação Luís Eduardo Magalhães, 2002.

TAQUARY, I. B.; FAGUNDES, P. S. Um histórico do planejamento urbano em Natal-RN. In: CONGRESSO NORTE-NORDESTE DE PESQUISA E INOVAÇÃO, 5., 2010, Maceió. Anais [...]. Maceió: IFAL, 2010. Disponível em: http://congressos.ifal.edu.br/index.php/connepi/CONNEPI2010/paper/ viewFile/917/642. Acesso em: 17 jun. 2017.

VASCONCELOS, D. A. L. de. Turistificação do espaço e exclusão social: a revitalização do bairro de Jaraguá, Maceio-AL, Brasil. Turismo em Análise, São Paulo, v. 16, n. 1, p. 47-67, maio 2005. 